\title{
Brain SPECT in mesial temporal lobe epilepsy \\ Comparison between visual analysis and SPM
}

\author{
Bárbara Juarez Amorim', Celso Darío Ramos', \\ Allan Oliveira dos Santos ${ }^{1}$, Mariana da Cunha Lopes de Lima', \\ Li Li Min², Edwaldo Eduardo Camargo', Fernando Cendes², \\ Elba Cristina Sá de Camargo Etchebehere ${ }^{1}$
}

\begin{abstract}
Objective: To compare the accuracy of SPM and visual analysis of brain SPECT in patients with mesial temporal lobe epilepsy (MTLE). Method: Interictal and ictal SPECTs of 22 patients with MTLE were performed. Visual analysis were performed in interictal (VISUAL(inter)) and ictal (VISUAL(ictal/inter)) studies. SPM analysis consisted of comparing interictal (SPM(inter)) and ictal SPECTs (SPM(ictal)) of each patient to control group and by comparing perfusion of temporal lobes in ictal and interictal studies among themselves (SPM(ictal/inter)). Results: For detection of the epileptogenic focus, the sensitivities were as follows: VISUAL(inter)=68\%; VISUAL(ictal/inter)=100\%; SPM(inter)=45\%; SPM(ictal)=64\% and SPM(ictal/inter)=77\%. SPM was able to detect more areas of hyperperfusion and hypoperfusion. Conclusion: SPM did not improve the sensitivity to detect epileptogenic focus. However, SPM detected different regions of hypoperfusion and hyperperfusion and is therefore a helpful tool for better understand pathophysiology of seizures in MTLE.

Key words: brain perfusion, SPECT, SPM, seizures, epilepsy.
\end{abstract}

SPECT cerebral na epilepsia de lobo temporal mesial: comparação entre análise visual e SPM

\section{RESUMO}

Objetivo: Comparar a acurácia do SPM com a análise visual na detecção do foco epileptogênico e alterações perfusionais à distância no SPECT cerebral. Método: Foram realizados os SPECTs ictal e interictal de 22 pacientes com epilepsia de lobo temporal mesial (ELTM). A análise visual foi realizada nos estudos interictal (VISUAL(inter)) e ictal (VISUAL(ictal/inter)). Na análise com SPM foi comparado o estudo interictal (SPM(inter)) e ictal (SPM(ictal)) de cada paciente com o grupo controle e comparou-se a perfusão dos lobos temporais entre os estudos ictal e interictal (SPM(ictal/inter)). Resultados: Para a detecção do foco epileptogênico, as sensibilidades foram as seguintes: VISUAL(inter)=68\%; VISUAL(ictal/inter) $=100 \% ;$ SPM(inter) $=45 \% ;$ SPM(ictal) $=64 \%$ and SPM(ictal/inter) $=77 \%$. 0 SPM foi capaz de detectar mais áreas de hiperperfusão e hipoperfusão. Conclusão: O SPM não aumentou a sensibilidade na detecção do foco epileptogênico. Entretanto, o SPM detectou diferentes regiões de hipoperfusão e hiperperfusão e portanto, ele pode ser uma ferramenta de ajuda para se melhor entender a patofisiologia das crises na ELTM.

Palavras-chave: SPECT cerebral, SPECT, SPM, crises, epilepsia.

\section{Correspondence}

Bárbara Juarez Amorim

Serviço de Medicina Nuclear Hospital das Clínicas da Unicamp

Caixa Postal 6142

13083-888 Campinas SP - Brasil

E-mail: juarezbarbara@hotmail.com

Received 24 June 2009

Received in final form 29 September 2009 Accepted 15 October 2009.
The most frequent type of epilepsy refractory to antiepileptic drugs is complex partial seizure and the majority of foci are in the temporal lobe ${ }^{1}$. Temporal lobe ep- ilepsy (TLE) is recognized as a specific syndrome ${ }^{2}$ because of its high prevalence. Nearly $60 \%$ of patients with mesial TLE (MTLE) present hypocampus sclerosis

School of Medical Sciences, Campinas State University (Unicamp), Campinas SP, Brazil: 'Division of Nuclear Medicine, Department of Radiology; ${ }^{2}$ Department of Neurology. 
on histological analysis ${ }^{3}$. Temporal lobe resection gives a complete or almost complete control of seizures in about $70 \%$ to $80 \%$ of patients ${ }^{4}$. The success of surgery relies on tests that can help identify the source and side of the seizures. Brain perfusion single photon emission computed tomography (SPECT) is an accurate method for detecting the origin of the seizure. These epileptogenic foci classically appear as a region of normal perfusion or hypoperfusion in the interictal study that becomes hyperperfused in ictal study. The specificity of this combination is nearly $100 \%$ by visual analysis alone. The sensitivity for detection of the origin of the epileptic focus in patients with TLE by the visual assessment of interictal SPECTs alone is about $44 \%$, while the sensitivity of the evaluation of the ictal SPECT study alone has a sensitivity of nearly $96 \%$. In addition to visual inspection, statistical parametric mapping (SPM) may be used to help localize the epileptic focus. SPM is a software that allows comparisons, voxel by voxel, of the radioactivity in the entire brain of the patient to a control group.

The majority of studies using SPM SPECT in epilepsy compare the entire patient population to the control group $^{6-8}$, while a few studies compare SPM SPECT of each patient to the control group. SPM sensitivity in ictal SPECT, in all these studies, ranges from $50 \%{ }^{6}$ to $89 \%{ }^{9}$. However, SPM sensitivities are not compared to visual analysis ${ }^{6,10-13}$. There are only two studies ${ }^{9,14}$ comparing SPM sensitivity to visual analysis in SPECT in patients with TLE.

In the present study, SPM SPECT analysis was performed comparing patients with chronic refractory MTLE to age-matched neurologically healthy controls.

We hypothesized that SPM SPECT may have a high sensitivity for detection of the epileptogenic focus and distant perfusion alterations if the SPM SPECT analysis was performed in the same manner as the visual analysis (by comparing the ictal and interictal studies). To our knowledge, this SPM SPECT analysis has not yet been described.

\section{METHOD}

\section{Patients and control group}

Twenty-two patients with chronic drug-refractory MTLE were studied (14 women, 8 men; mean age: 28 years). All patients were submitted to serial eletrencephalography (EEG), long-term-video-EEG monitoring, magnetic resonance imaging (MRI) and ictal and interictal brain SPECT imaging. The side of the epileptogenic focus was determined by evaluation of the clinical data, EEG findings, long-term-video-EEG and MRI. Histopathological analysis and surgical outcome data were used to confirm the side and exact location of the epileptogenic focus in $18 / 22$ patients $(82 \%)$.

The control group consisted of 50 healthy volunteers with ages between 25 and 53 years, mean age 31 years, 29 women and 21 men.

All patients signed an informed consent and the study was approved by the Ethics Committee of the School of Medical Sciences, Campinas State University (Unicamp), Campinas SP, Brazil.

\section{Electroencephalography}

All patients underwent serial routine EEG recording using the 10-20 system with additional anterior temporal and zygomatic electrodes. They were also submitted to long-term-video-EEG monitoring with scalp electrodes for seizure recording.

\section{Magnetic resonance imaging (MRI)}

MRI was performed in a $2.0 \mathrm{~T}$ scanner (Elscint Prestige, Haifa, Israel). The imaging protocol consisted of: (a) sagital $\mathrm{T} 1$ spin-echo, $6 \mathrm{~mm}$ thick $(\mathrm{TR}=430, \mathrm{TE}=12)$ for optimal orientation of the subsequent images; (b) coronal T1 inversion recovery (IR), $3 \mathrm{~mm}$ thick (flip angle $=200^{\circ}$; $\mathrm{TR}=2700, \mathrm{TE}=14, \mathrm{TI}=840$, matrix $=130 \times 256, \mathrm{FOV}=$ $16 \times 18 \mathrm{~cm}$ ); (c) coronal T2-weighted "fast spin-echo" (FSE), 3-4mm thick (flip angle $=120^{\circ}, \mathrm{TR}=4800, \mathrm{TE}=129$, matrix $=252 \times 320, F O V=18 \times 18 \mathrm{~cm}$ ); (d) axial images parallel to the long axis of the hippocampus; T1 gradient echo (GRE), $3 \mathrm{~mm}$ thick (flip angle $=70^{\circ}, \mathrm{TR}=200$, $\mathrm{TE}=5$, matrix $=180 \times 232, \mathrm{FOV}=22 \times 22 \mathrm{~cm})$; (e) axial T2 FSE, $4 \mathrm{~mm}$ thick (flip angle $=120^{\circ}$, TR=6800, TE $=129$, matrix $=252 \times 328, F O V=21 \times 23 \mathrm{~cm}$ ); (f) volumetric (3D) T1 GRE, acquired in the sagital plane for multiplanar reconstruction, $1 \mathrm{~mm}$ thick (flip angle $=35^{\circ}, \mathrm{TR}=22, \mathrm{TE}=9$, matrix $=256 \times 220, \mathrm{FOV}=23 \times 25 \mathrm{~cm}$ ).

Visual analysis of MRI and multi-planar reconstruction were systematically performed in a workstation $(\mathrm{O} 2$ Silicon Grafic) using the Omnipro software (Elscint Prestige, Haifa, Israel).

\section{Brain SPECT acquisition}

Both interictal and ictal studies were acquired for all patients. For all the control participants as well as for the patients' interictal scans, the participants were asked to rest in a dark, quiet room for 15 minutes, with a permanent intravenous access through a butterfly connected to a catheter with saline solution. While at rest, 1110 $\mathrm{MBq}\left(30 \mathrm{mCi}\right.$ ) of ${ }^{99 \mathrm{~m}} \mathrm{Tc}-\mathrm{ECD}$ was injected. The participants rested for another 10 minutes prior to the SPECT acquisition.

The ictal SPECTs were acquired during an epileptic seizure. The anti-epileptic drugs were reduced in some of these patients. Patients were asked to rest while longterm-video-EEG monitoring was performed for seizure recording. They remained with a permanent intravenous access through a butterfly connected to a catheter with 
saline solution. To ensure a fast injection of the radiopharmaceutical, the syringe was connected to the catheter and protected with a lead shield. Upon seizure onset, $1110 \mathrm{MBq}$ (30 mCi) of ${ }^{99 \mathrm{~m}} \mathrm{Tc}-\mathrm{ECD}$ was injected as quickly as possible. Seizures were confirmed by the EEG and video recordings. SPECT images were acquired 30-90 minutes after cessation of the seizure and stabilization of patient symptoms.

All SPECT images were performed in a computed scintillation camera with a fan-beam collimator. Sixty images were acquired in a $64 \times 64$ matrix, every 6 degrees, in a total of 360 degrees. Raw data were reconstructed by filtered back projection and attenuation correction was performed using Chang's method with a 0.115 attenuation coefficient. Images were displayed in the transaxial, coronal, sagital and temporal (parallel slices to the longest axis of the temporal lobe) planes for interpretation.

\section{Visual analysis}

Qualitative analysis was performed by two experienced nuclear physicians who searched for regions of hypoperfusion or hyperperfusion in the brain SPECT images by comparing the perfusion in the cortical and subcortical regions with the perfusion in the cerebellum and looking for hemisphere asymmetries. The observers were aware that all patients had MTLE but blinded from all other patient clinical data.

The visual analysis of the interictal SPECTs were labeled VISUAL(inter) and were analyzed by looking for regions of hypoperfusion in the temporal lobes.

The ictal SPECTs were named VISUAL(ictal/inter) and were analyzed by looking for regions of hypeperfusion in the temporal lobes during the ictal study that was hypoperfused or had normal perfusion in the interictal study. In the VISUAL(ictal/inter) analysis, distant regions of hyper and hypoperfusion were also evaluated.

\section{Processing of images in SPM}

The reconstructed SPECT images were converted into the Analyze format using MRIcro software (www.mricro.com). In this software the SPECTs from patients with left epileptogenic focus were left-right flipped, in order to evaluate all MTLE patients as a single group (thus all epileptogenic foci were on the right hemisphere). Voxel-based analysis was performed using SPM2 (Wellcome Department of Cognitive Neurology, www.fil.ion.ucl. ac.uk). To allow group comparison, the size and shape of each individual's scans were normalized to stereotaxic space (warping each image to match the default SPECT template that is distributed with SPM2). This process involves a 12 parameter linear transformation. The normalized images were smoothed by convolution with an Isotropic Gaussian Kernel (FWHM) of $6 \mathrm{~mm}$. The ${ }^{99 \mathrm{~m}} \mathrm{Tc}-$
ECD distribution was standardized to the mean global uptake using a proportional scale.

\section{SPM analysis}

The following SPM analyses were performed using a two-sample t-test:

1. SPM(inter) - The interictal SPECTs of each patient was compared to the control group, similar to visual anal$y$ sis for detection of the epileptogenic focus ( $<<0.05$; cluster $\geq 32$ voxels). Only perfusion alterations in the temporal lobes were analyzed. The epileptogenic focus was considered a true positive study if the perfusion in the focus was lower than the perfusion in the contralateral temporal lobe.

2. SPM(ictal) - The ictal SPECT from each patient was compared to the control group. In this analysis all regions of hyper and hypoperfusion were considered $(\mathrm{p}<0.05$; cluster $\geq 32$ voxels).

The epileptogenic focus was determined (a true positive study) if the perfusion in the focus was higher than the perfusion in the contralateral temporal lobe.

The time of injection was compared with perfusion alterations using the Spearman's correlation coefficient; $\mathrm{p}<0.05$.

Areas of hyperperfusion were correlated among themselves using the Spearman's correlation coefficient; $\mathrm{p}<0.05$. These areas were the temporal lobes, frontal lobes, parietal lobes, basal ganglia bilaterally and the cerebellar hemispheres.

3. SPM(ictal/inter) - The perfusion of the temporal lobes in the ictal and interictal studies were correlated. This analysis was performed to improve the sensitivity of SPM and to approximate the SPM with the clinical practice.

\section{RESULTS}

\section{Patient group}

Among the 22 patients studied, nine patients were classified as having right temporal lobe foci, eight as having left temporal lobe foci and five as asymmetric bilateral foci (Table 1).

The five patients with bilateral foci had asymmetric hippocampal atrophy on MRI and a predominance of the epileptiforme abnormalities and seizure onsets in one side, on the video-EEG recordings.

Eighteen patients were submitted to surgery. Histopathological analysis showed mesial temporal sclerosis in 9 patients, subpial gliosis in 2 patients and a glial nodule in 1 patient. In 6 patients, the tissue sample was insufficient for proper histopathological evaluation. Thirteen patients (72\%) were classified as Engel class I, four patients (22\%) as Engel class II and one (6\%) as Engel class III ${ }^{15}$. The four remaining patients are scheduled for surgery. 
Table 1. Patient data.

\begin{tabular}{|c|c|c|c|c|c|c|c|c|c|c|}
\hline Patient & Gender & Age (yrs) & MRI & $\begin{array}{l}\text { Focus } \\
\text { side* }^{*}\end{array}$ & $\begin{array}{l}\text { Visual (ictal) } \\
\text { Focus side }\end{array}$ & $\begin{array}{l}\text { Time to } \\
\text { injection } \\
\text { (seconds) }\end{array}$ & $\begin{array}{c}\text { Surgically } \\
\text { removed } \\
\text { side }\end{array}$ & Histology & $\begin{array}{c}\text { Follow-up } \\
\text { (months) }\end{array}$ & $\begin{array}{l}\text { Engel } \\
\text { classif. }\end{array}$ \\
\hline 1 & $\mathrm{~F}$ & 13 & BMTLS (+R) & $B(+R)$ & $\mathrm{R}$ & 20 & - & - & - & - \\
\hline 2 & $\mathrm{~F}$ & 45 & BMTLS (+L) & $B(+L)$ & $\mathrm{L}$ & 23 & L & MTLS & 53 & I \\
\hline 3 & $\mathrm{~F}$ & 42 & MTLS L & L & $\mathrm{L}$ & 5 & $\mathrm{~L}$ & MTLS & 23 & I \\
\hline 4 & M & 19 & $\mathrm{NL}$ & $L$ & $L$ & 10 & - & - & - & - \\
\hline 5 & $F$ & 36 & ETM R & $\mathrm{R}$ & $\mathrm{R}$ & 10 & $\mathrm{R}$ & MTLS & 57 & I \\
\hline 6 & $F$ & 17 & MTLS R & $\mathrm{R}$ & $\mathrm{R}$ & 5 & $\mathrm{R}$ & MTLS & 18 & I \\
\hline 7 & F & 33 & MTLSR & $\mathrm{R}$ & $\mathrm{R}$ & 24 & $\mathrm{R}$ & SPG & 62 & I \\
\hline 8 & M & 28 & $\mathrm{NL}$ & $L$ & $L$ & - & L & ITS & 73 & $\|$ \\
\hline 9 & $\mathrm{~F}$ & 31 & MTLSR & $\mathrm{R}$ & $\mathrm{R}$ & 10 & $\mathrm{R}$ & MTLS & 12 & 1 \\
\hline 10 & M & 9 & MTLS L & $\mathrm{L}$ & $\mathrm{L}$ & 10 & - & - & - & - \\
\hline 11 & M & 45 & BMTLS (+R) & $B(+R)$ & $\mathrm{R}$ & 8 & $\mathrm{R}$ & SPG & 60 & III \\
\hline 12 & $\mathrm{~F}$ & 41 & MTLS R & $\mathrm{R}$ & $\mathrm{R}$ & - & $\mathrm{R}$ & ITS & 99 & 1 \\
\hline 13 & M & 26 & MTLS R & $\mathrm{R}$ & $\mathrm{R}$ & 13 & $\mathrm{R}$ & MTLS & 19 & 1 \\
\hline 14 & $\mathrm{~F}$ & 43 & ETM B (+L) & $B(+L)$ & $L$ & 30 & $L$ & ITS & 80 & II \\
\hline 15 & $F$ & 32 & MTLS L & $\mathrm{L}$ & $L$ & 21 & $\mathrm{~L}$ & GN & 99 & 1 \\
\hline 16 & $\mathrm{~F}$ & 41 & MTLS R & $\mathrm{R}$ & $\mathrm{R}$ & 40 & $\mathrm{R}$ & MTLS & 69 & I \\
\hline 17 & M & 21 & MTLS L & $L$ & $\mathrm{~L}$ & 10 & - & - & - & - \\
\hline 18 & M & 10 & TD R & $\mathrm{R}$ & $\mathrm{R}$ & 10 & $\mathrm{R}$ & ITS & 44 & II \\
\hline 19 & M & 20 & MTLS L & $L$ & $L$ & 11 & $\mathrm{~L}$ & MTLS & 57 & 1 \\
\hline 20 & $\mathrm{~F}$ & 32 & BMTLS (+R) & $B(+R)$ & $\mathrm{R}$ & 10 & $\mathrm{R}$ & ITS & 5 & I \\
\hline 21 & $\mathrm{~F}$ & 17 & MTLS R & $\mathrm{R}$ & $\mathrm{R}$ & 4 & $\mathrm{R}$ & ITS & 91 & $\|$ \\
\hline 22 & $\mathrm{~F}$ & 16 & MTLS L & $L$ & $L$ & 30 & $\mathrm{~L}$ & MTLS & 35 & I \\
\hline Mean & - & 28 & - & - & - & 15 & - & - & 53 & - \\
\hline SD & - & 11.9 & - & - & - & 9.8 & - & - & 29.6 & - \\
\hline
\end{tabular}

*According to the clinical data, EEGs, telemetry and MRI. R: right; L: left; B: bilateral; +R or +L: more intense on the right or left side; TD: temporal lobe dysplasia; MTLS: medial temporal lobe sclerosis; F: female; M: male ; GSP: subpial gliosis; ITS: insufficient tissue sample; NL: normal; GN: glial nodule; SD: standard deviation.

There were no significant differences among the control and patient groups in relation to gender $(\mathrm{p}=0.2018$; Chi-square test) or age ( $\mathrm{p}=0.3294$; Mann-Whitney test).

The mean time of the radiotracer injection after the beginning of the seizure was 15 seconds (from 4 to 40 seconds).

\section{Visual analysis}

1. VISUAL(inter) - In the interictal study, temporal lobe hypoperfusion (the epileptogenic focus) was observed in 15 patients (sensitivity of 68\%). Two patients had hypoperfusion in both temporal lobes and therefore their studies were not considered as true positive. These two patients had bilateral foci.

2. VISUAL(ictal/inter) - In the ictal study, temporal lobe hyperperfusion (epileptogenic focus) was observed in all 22 patients, including one patient with a normal MRI. This patient was classified as Engel II after surgery.
Ipsilateral hyperperfusion of the basal ganglia was observed in 12 patients and bilateral basal ganglia hyperperfusion, in two patients. Other hyperperfused regions were the ipsilateral thalamus $(2 / 22)$, contralateral thalamus $(1 / 22)$, bilateral thalami $(2 / 22)$, ipsilateral cerebellar hemisphere (1/22) and contralateral temporal lobe (1/22).

Hypoperfused regions were also noted during seizure and these included the bilateral frontal lobes (7/22), ipsilateral frontal lobe $(3 / 22)$, diffuse cortical hypoperfusion (4/22), bilateral parieto-occipital region (1/22), ipsilateral parieto-occipital region $(1 / 22)$, contralateral parietal lobe (1/22), ipsilateral parietal lobe $(1 / 22)$ and contralateral temporal lobe (1/22).

\section{SPM analysis}

1. SPM(inter) - The epileptogenic focus was detected in ten patients (sensitivity of $45 \%$ ). Two studies were considered false positive because hypoperfusion in the con- 

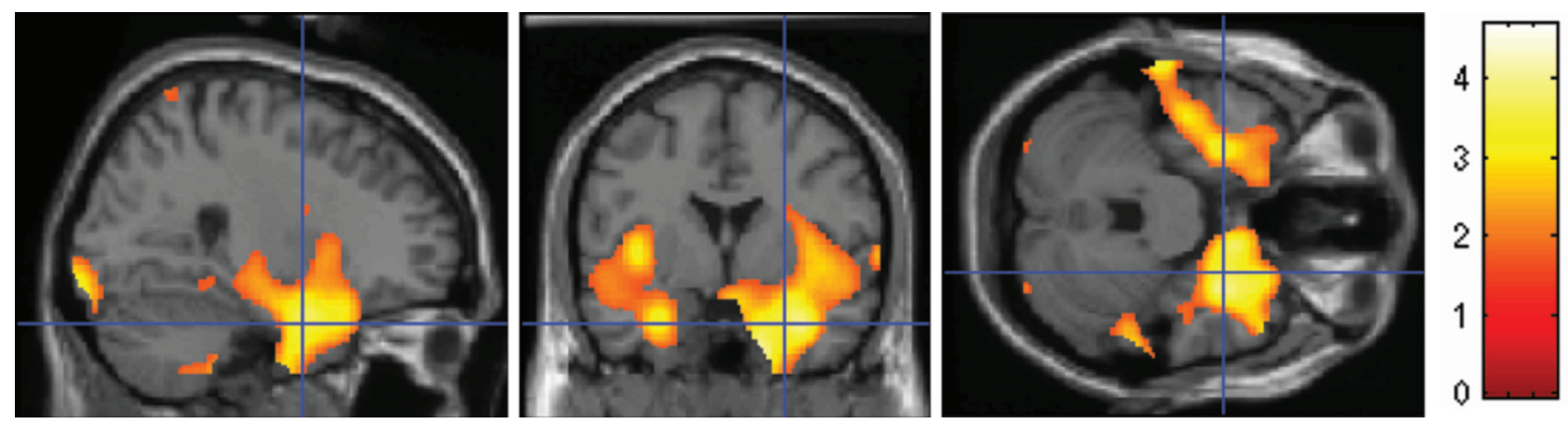

Fig 1. SPM(ictal) result from one patient ( $p<0.05$ ). It is observed a marked hyperperfusion in the mesial ipsilateral temporal lobe (epileptogenic focus) and a less intense hyperperfusion in the contralateral temporal lobe.

Table 2. Areas of distant hyper and hypoperfusion identified in SPM(ictal) $(p<0.05)$.

\begin{tabular}{lcc}
\hline & \multicolumn{2}{c}{ Frequency } \\
\cline { 2 - 3 } Brain region & Hyperperfusion & Hypoperfusion \\
\hline Ipsilateral temporal lobe (epileptogenic focus) & $73 \%$ & $59 \%$ \\
Contralateral temporal lobe & $64 \%$ & $59 \%$ \\
Ipsilateral frontal lobe & $68 \%$ & $86 \%$ \\
Contralateral frontal lobe & $55 \%$ & $77 \%$ \\
Ipsilateral parietal lobe & $77 \%$ & $64 \%$ \\
Contralateral parietal lobe & $64 \%$ & $59 \%$ \\
Ipsilateral occipital lobe & $68 \%$ & $45 \%$ \\
Contralateral occipital lobe & $68 \%$ & $45 \%$ \\
Ipsilateral parieto-occipital region & $41 \%$ & - \\
Contralateral parieto-occipital region & $50 \%$ & - \\
Ipsilateral cerebellar hemisphere & $59 \%$ & $59 \%$ \\
Contralateral cerebellar hemisphere & $59 \%$ & $41 \%$ \\
Vermis & $32 \%$ & $27 \%$ \\
Pons & $36 \%$ & $23 \%$ \\
Ipsilateral basal ganglia & $50 \%$ & $18 \%$ \\
Contralateral basal ganglia & $27 \%$ & $14 \%$ \\
Ipsilateral thalamus & $45 \%$ & $14 \%$ \\
Contralateral thalamus & $50 \%$ & $14 \%$ \\
Ipsilateral insula & $45 \%$ & $9 \%$ \\
Contralateral insula & $27 \%$ & $18 \%$ \\
\hline
\end{tabular}

tralateral temporal lobe was more significant than in the epileptogenic focus.

2. SPM(ictal) - The epileptogenic focus was detected in 14 patients (sensitivity of 64\%) (Fig 1). There were two studies considered false positive because hyperperfusion was more significant in the contralateral temporal lobe. The distant perfusion alterations detected by this analysis are displayed in Table 2.

There were no significant correlations between injection time and regions of hyperperfusion $(\mathrm{p}=0.4098$; $\mathrm{p}=0.0727)$ (Fig 2) and hypoperfusion ( $\mathrm{p}=-0.3026$; $\mathrm{p}=0.1946$ ) (Fig 3). There was a tendency to find more re- gions of hyperperfusion when the time elapsed between the onset of seizure and injection was longer. In contrast, there was a tendency to find more regions of hypoperfusion when the time elapsed between the onset of seizure and injection was shorter.

Hyperperfusion in the epileptogenic focus correlated strongly with hyperperfusion in the contralateral temporal lobe, ipsilateral frontal and contralateral frontal and ipsilateral cerebellar hemisphere. Hyperperfusion in the ipsilateral frontal lobe had a strong correlation with the contralateral frontal lobe, the ipsilateral cerebellar hemisphere and the contralateral cerebellar hemisphere. Con- 


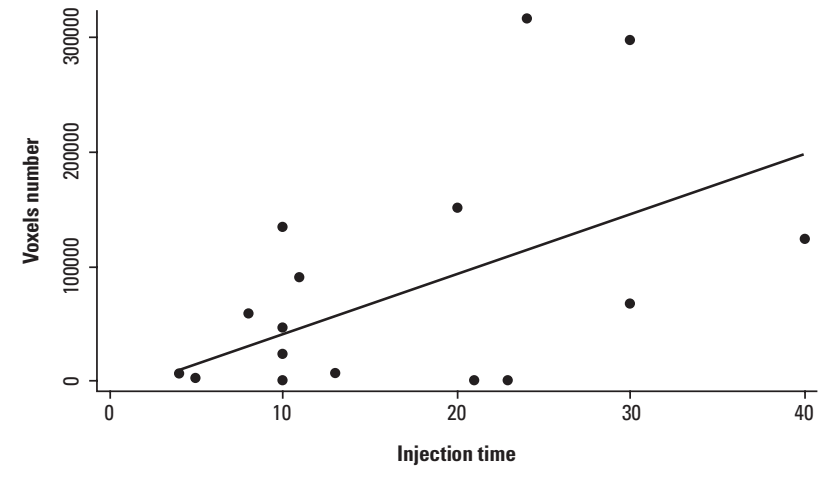

Fig 2. Dispersion of hyperperfusion voxels versus the injection time.

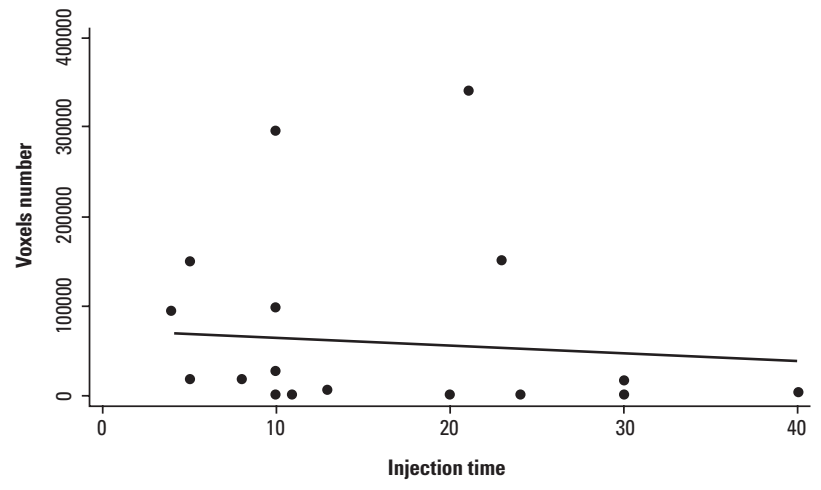

Fig 3. Dispersion of hypoperfusion voxels versus the injection time.

Table 3. Correlation among areas of hyperperfusion (Spearman's coefficient and p-values).

\begin{tabular}{|c|c|c|c|c|c|c|c|c|c|c|c|}
\hline & & \multicolumn{2}{|c|}{ Temporal } & \multicolumn{2}{|c|}{ Basal ganglia } & \multicolumn{2}{|c|}{ Frontal } & \multicolumn{2}{|c|}{ Cerebellum } & \multicolumn{2}{|c|}{ Parietal } \\
\hline & & 1 & $\mathrm{C}$ & 1 & C & 1 & C & 1 & C & 1 & C \\
\hline \multirow[t]{2}{*}{ Temporal } & I & 1.00 & & & & & & & & & \\
\hline & C & $\begin{array}{c}0.92 \\
0.0000\end{array}$ & 1.00 & & & & & & & & \\
\hline \multirow[t]{2}{*}{ Basal ganglia } & I & $\begin{array}{c}0.72 \\
0.0002\end{array}$ & $\begin{array}{c}0.72 \\
0.0002\end{array}$ & 1.00 & & & & & & & \\
\hline & C & $\begin{array}{c}0.57 \\
0.0056\end{array}$ & $\begin{array}{c}0.58 \\
0.0046\end{array}$ & $\begin{array}{c}0.74 \\
0.0001\end{array}$ & 1.00 & & & & & & \\
\hline \multirow[t]{2}{*}{ Frontal } & I & $\begin{array}{c}0.86 \\
0.0000\end{array}$ & $\begin{array}{c}0.78 \\
0.0000\end{array}$ & $\begin{array}{c}0.70 \\
0.0003\end{array}$ & $\begin{array}{c}0.55 \\
0.0074\end{array}$ & 1.00 & & & & & \\
\hline & C & $\begin{array}{c}0.81 \\
0.0000\end{array}$ & $\begin{array}{c}0.78 \\
0.0000\end{array}$ & $\begin{array}{c}0.62 \\
0.0020\end{array}$ & $\begin{array}{c}0.58 \\
0.0049\end{array}$ & $\begin{array}{c}0.90 \\
0.0000\end{array}$ & 1.00 & & & & \\
\hline \multirow[t]{2}{*}{ Cerebellum } & I & $\begin{array}{c}0.81 \\
0.0000\end{array}$ & $\begin{array}{c}0.77 \\
0.0000\end{array}$ & $\begin{array}{c}0.63 \\
0.0018\end{array}$ & $\begin{array}{c}0.52 \\
0.0136\end{array}$ & $\begin{array}{c}0.87 \\
0.0000\end{array}$ & $\begin{array}{c}0.93 \\
0.0000\end{array}$ & 1.00 & & & \\
\hline & C & $\begin{array}{c}0.74 \\
0.0001\end{array}$ & $\begin{array}{c}0.77 \\
0.0000\end{array}$ & $\begin{array}{c}0.67 \\
0.0006\end{array}$ & $\begin{array}{c}0.65 \\
0.0012\end{array}$ & $\begin{array}{c}0.84 \\
0.0000\end{array}$ & $\begin{array}{c}0.81 \\
0.0000\end{array}$ & $\begin{array}{c}0.77 \\
0.0000\end{array}$ & 1.00 & & \\
\hline \multirow[t]{2}{*}{ Parietal } & I & $\begin{array}{c}0.79 \\
0.0000\end{array}$ & $\begin{array}{c}0.74 \\
0.0001\end{array}$ & $\begin{array}{c}0.57 \\
0.0057\end{array}$ & $\begin{array}{c}0.38 \\
0.0796\end{array}$ & $\begin{array}{c}0.79 \\
0.0000\end{array}$ & $\begin{array}{c}0.69 \\
0.0004\end{array}$ & $\begin{array}{c}0.69 \\
0.0004\end{array}$ & $\begin{array}{c}0.71 \\
0.0002\end{array}$ & 1.00 & \\
\hline & C & $\begin{array}{c}0.65 \\
0.0011\end{array}$ & $\begin{array}{c}0.65 \\
0.0011\end{array}$ & $\begin{array}{c}0.61 \\
0.0024\end{array}$ & $\begin{array}{c}0.41 \\
0.0566\end{array}$ & $\begin{array}{c}0.75 \\
0.0001\end{array}$ & $\begin{array}{c}0.77 \\
0.0000\end{array}$ & $\begin{array}{c}0.75 \\
0.0001\end{array}$ & $\begin{array}{c}0.71 \\
0.0002\end{array}$ & $\begin{array}{c}0.77 \\
0.0000\end{array}$ & 1.00 \\
\hline
\end{tabular}

C; contralateral; I: ipsilateral.

tralateral frontal lobe hyperperfusion had a strong correlation with the ipsilateral cerebellar hemisphere and the contralateral cerebellar hemisphere (Table 3).

3. SPM(ictal/inter) - The detection of the epileptogenic focus by this methodology had a sensitivity of $77 \%$ which was higher than the sensitivity of $64 \%$ from the SPM(ictal). The two false positive studies seen in the $\mathrm{SPM}(\mathrm{ictal})$ analysis were considered true positive in this analysis, since the perfusion in the epileptogenic focus was compared among the ictal and interictal studies, and not among lobe hemispheres in the same study.

\section{DISCUSSION}

SPM has been already performed in the TLE patients ${ }^{7,8,12,16}$. We previously studied a group of MTLE using $\mathrm{SPM}^{16}$ and did not find significant areas of hypoperfusion in the interictal SPECT images. However, we did find significant hyperperfusion in the temporal lobe (epileptogenic focus) in the ictal SPECT images. This type of group analysis is helpful only to describe a pathological behavior in a group of patients with a specific disorder, but is not helpful to detect the epileptogenic focus in an individual patient. 
The voxel based statistical analysis with SPM has increasingly become more useful in neuroimaging, however only two studies compare SPM and visual analysis sensitivities ${ }^{9,14}$. In the present study, SPM was used in order to increase the detection of the epileptogenic focus and also help identify distant perfusion alterations.

The VISUAL(inter) analysis had a sensitivity of 68\% which was slightly higher than the interictal SPECT sensitivity reported in the literature. In the metanalysis by Devous et al. ${ }^{5}$ their sensitivity was of $44 \%$ for TLE, and included almost only visual analysis. A possible explanation for the high sensitivity in our study is that the nuclear medicine physicians analyzed the interictal and ictal SPECTs together, possibly overestimating alterations seen in the interictal studies.

Sensitivity of SPM(inter) analysis was $45 \%$, which was lower than the VISUAL(inter) analysis. Two false positive cases were due to patients with bilateral temporal lobe sclerosis on MR images, with predominance on one side.

VISUAL(ictal/inter) analysis had a sensitivity of 100\% which was similar to the $97 \%$ sensitivity described by Devous et al. ${ }^{5}$.

Detection of the epileptogenic focus by the SPM(ictal) had a sensitivity of $64 \%$. This sensitivity was inferior to the VISUAL(ictal) analysis. Studies have shown the SPM sensitivity to range from $50 \%{ }^{6}$ to $89 \%{ }^{9}$. Only two studies ${ }^{9,14}$ performed a comparison between SPM and visual analysis and both found identical sensitivities: $80 \%$ sensitivity by Bruggeman et al. ${ }^{14}$ and $89 \%$ sensitivity by Lee et al. ${ }^{9}$.

The SPM(ictal/inter) analysis showed the highest sensitivity (77\%) among the SPM analyses. We tried to approximate the SPM analysis to the visual analysis performed in routine clinical practice in order to observe the capacity of SPM to detect the epileptogenic focus, and still, VISUAL(ictal/inter) showed a higher sensitivity (100\% vs $77 \%)$.

There are two possibile explanations for the lower sensitivity of SPM(ictal/inter) compared to the VISUAL(ictal/ inter) analysis:

1. A $64 \times 64$ matrix was used to perform these studies, which has a lower resolution and could pose as a problem in the SPM processing. Even so, the SPM sensitivities obtained in this study were very similar to that described in the literature.

2. Variation of image signal due to differences in the injected and absorbed doses. A global normalization of SPM images is performed. However, when there is a large variation, this normalization may not be sufficient and most commonly occurs in the ictal studies because the global increase in brain metabolism is assymetric among patients.

SPM did not have a better performance than visual analysis for detection of the epileptogenic focus. How- ever, SPM was able to detect more areas hyperperfusion and hypoperfusion in the brain.

VISUAL(ictal/inter) analysis detected basal ganglia hyperperfusion in $55 \%$ of patients while in the SPM(inter) this finding was noted in $50 \%$ of the patients. Basal ganglia have many connections with the frontal and temporal lobes and hyperperfusion in this region is probably due to activation of the corticostriatal pathway ${ }^{17,18}$. Activation of the basal ganglia, which can occur in MTLE, can stimulate the corticopontocerebellar pathways and cause hyperperfusion in contralateral cerebellar hemisphere as well ${ }^{19-}$ ${ }^{21}$. However, Marks et al..$^{22}$ observed that in TLE, contralateral cerebellar hyperperfusion occurs mainly secondary to ipsilateral frontal lobe hyperperfusion, since the temporal lobe only has a few bilateral projections to the cerebellum. This description by Marks et al. ${ }^{22}$ was confirmed in our study in the SPM(ictal/inter) analysis because frontal lobe hyperperfusion had a strong correlation with cerebellar hemisphere hyperperfusion.

SPM(ictal/inter) analysis detected hyperperfusion in both occipital lobes in $68 \%$ of patients. This was probably due to hyperactivation of these regions because injection was performed without supression of lights, in contrast to control individuals, in which the radiotracer injection was performed in a dark room.

SPM detected more distant areas of hypoperfusion in relation to visual analysis. The finding of bilateral frontal lobe hypoperfusion was similar to the study of Van Paesschen et al. ${ }^{7}$, and may be explained by a deviation of flow to the temporal lobe $e^{23}$, absence of cognitive processes during seizure $^{24}$ and ictal inhibition in regions near the focus ${ }^{25}$.

Areas of hypoperfusion have to be interpreted with caution since there is strong evidence from EEG and SPECT findings that there is an increase in neural activity and global perfusion during the early phase of seizure. In the present analysis the global perfusion was normalized to minimize the variables in the administered and absorbed doses, and therefore, hypoperfusion could be relative to other regions with extremely high levels of perfusion.

An interesting finding in the SPM(ictal) was the tendency to find more areas of hyperperfusion as the time between radiotracer injection and the beginning of the seizure increased. The more regions of hyperperfusion could be explained by global neuronal activation due to seizure generalization. In contrast, there was a tendency to observe more areas of hypoperfusion as the time between radiotracer injection and the beginning of the seizure decreased. The more regions of hypoperfusion could be explained by a global neuronal deactivation as a defense mechanism to avoid seizure generalization. Studies with more patients are necessary to confirm these findings.

In conclusion, SPM did not improve the sensitivity to detect the epileptogenic focus. However, SPM detect- 
ed different regions of hypo and hyperperfusion and is therefore a helpful tool for the better understanding the pathophysiology of seizures in MTLE.

\section{REFERENCES}

1. Rowe CC, Berkovic SF, Sia STB, et al. Localization of epileptic foci with postictal single photon emission computed tomography. Ann Neurol 1989;26: 660-668.

2. Engle JrJ. Epileptic syndromes. In: Engel Jr J (Ed). Seizures and epilepsy. Philadelphia: FA Davis Company, 1989:195-201.

3. Babb TL, Brown WJ, Pretorius J, Davenport C, Lieb JP, Crandall PH. Temporal lobe volumetric cell densities in temporal lobe epilepsy. Epilepsia 1984;25: 729-740.

4. Engle Jr J. Outcome with respect to epileptic seizures. In: Engel Jr J (Ed). Surgical treatment of the epilepsies. New York: Raven Press, 1987:553-571.

5. Devous MD, Thisted RA, Morgan GF, Leroy RF, Rowe CC. SPECT brain imaging in epilepsy: a meta-analysis. J Nucl Med 1998;39:285-293.

6. Lee JD, Kim HJ, Lee BI, Kim OJ, Jeon TJ, Kim MJ. Evaluation of ictal brain SPET using statistical parametric mapping in temporal lobe epilepsy. Eur J Nucl Med 2000;27:1658-1665.

7. Van Paesschen W, Dupont P, Driel GV, Billoen HV, Maes A. SPECT perfusion changes during complex parcial seizures in patients with hippocampal sclerosis. Brain 2003;126:1103-1111.

8. Blumenfeld $\mathrm{H}, \mathrm{McN}$ ally $\mathrm{KA}$, Vanderhill SD, et al. Positive and negative network correlations in temporal lobe epilepsy. Cerebral Cortex 2004;14:892-902.

9. Lee JJ, Kang WJ, Lee DS, et al. Diagnostic performance of ${ }^{18}$ F-FDG PET and ictal ${ }^{99 \mathrm{~m} T \mathrm{~T}-H M P A O}$ SPET in pediatric temporal lobe epilepsy: Quantitative analysis by statistical parametric mapping, statistical probabilistic anatomical map, and subtraction ictal SPET. Seizure 2005;14:213-220.

10. Lee DS, Lee JS, Kang KW, et al. Disparity of perfusion and glucose metabolism of epileptogenic zones in temporal lobe epilepsy demonstrated by SPM/ SPAM analysis on ${ }^{15} \mathrm{O}$ water PET, $\left[{ }^{18} \mathrm{~F}\right] \mathrm{FDG}-\mathrm{PET}$, and $\left[{ }^{99 \mathrm{~m}} \mathrm{TC}\right]-\mathrm{HMPAO}$ SPECT. Epilepsia 2001;42:1515-1522.

11. Chang DJ, Zubal IG, Gottschalk C, et al. Comparison of statistical parametric mapping and SPECT difference imaging in patients with temporal lobe epilepsy. Epilepsia 2002;43:68-74
12. Tae WS, Joo EY, Kim JH, et al. Cerebral perfusion changes in mesial temporal lobe epilepsy: SPM analysis of ictal and interictal SPECT. Neuroimage 2005; 24:101-110.

13. McNally KA, Paige AL, Varghese $G$, et al. Localizing value of ictal-interictal SPECT analyzed by SPM ISAS. Epilepsia 2005;46:1450-1464.

14. Bruggemann JM, Som SS, Lawson JA, Haidl W, Cuningham AM, Bye AME. Application of statistical parametric mapping to SPET in the assessment of intractable childhood epilepsy. Eur J Nucl Med Mol Imaging 2004;319:369-377.

15. Engel Jr J, Ness PCV, Rasmussen T, Ojeman LM. Outcome with respect to epileptic seizures. In: Engel Jr J (Ed). Surgical treatment of the epilepsies. New York: Raven Press, 1993:609-621.

16. Amorim BJ, Etchebehere ECSC, Camargo EC, et al. Statistical voxel-wise analysis of ictal SPECT reveals pattern of abnormal perfusion in patients with temporal lobe epilepsy. Arq Neuropsiquiatr 2005;63:977-983.

17. Yang CR, Mongenson GJ. An electrophysiological study of the neural projection from the hippocampus to the ventral pallidum and the subpallidal areas by way of the nucleus accubens. Neuroscience 1985;15:1015-1024.

18. Dupond S, Semah F, Baulac M, Samson Y. The underlying pathophysiology of ictal dystonia in temporal lobe epilepsy. Neurology 1998;51:1289-1292.

19. Won JH, Lee JD, Chung TS, Park CY, Lee BI. Increased contralateral cerebellar uptake of technetium-99m-HMPAO on ictal brain SPECT. J Nucl Med 1996;37:426-429.

20. Bohnen $\mathrm{NI}, \mathrm{O}^{\prime}$ Brien TJ, Mullan BP, So EL. Cerebellar changes in partial seizures: clinical correlations of quantitative SPECT and MRI analysis. Epilepsia 1998; 39:640-650.

21. Shin WC, Hong SB, Tae WS, Seo DW, Kim SE. Ictal hyperperfusion of cerebellum and basal ganglia in temporal lobe epilepsy: SPECT subtraction with MRI coregistration. J Nucl Med 2001;42:853-858.

22. Marks DA, Katz A, Hoffer P, Spencer SS. Localization of extratemporal epileptic foci during ictal single photon emission computed tomography. Ann Neurol 1992;31:250-255.

23. Rabinowicz AL, Salas E, Beserra F, Leiguarda RC, Vazquez SE. Changes in regional cerebral blood flow beyond the temporal lobe in unilateral temporal lobe epilepsy. Epilepsia 1997:38:1011-1014.

24. Fuster JM. The prefrontal cortex - an update: time is of the essence. Neuron 2001;30:319-333.

25. Prince DA, Wilder BJ. Control mechanisms in cortical epileptogenic foci. "Surround" inhibition. Arch Neurol 1967:16:194-202. 